Document downloaded from:

http://hdl.handle.net/10251/163283

This paper must be cited as:

Buitrago, M.; Bertolesi, E.; Calderón García, PA.; Adam, JM. (2021). Robustness of steel truss bridges: laboratory testing of a full-scale 21-metre bridge span. Structures. 29:691-700. https://doi.org/10.1016/j.istruc.2020.12.005

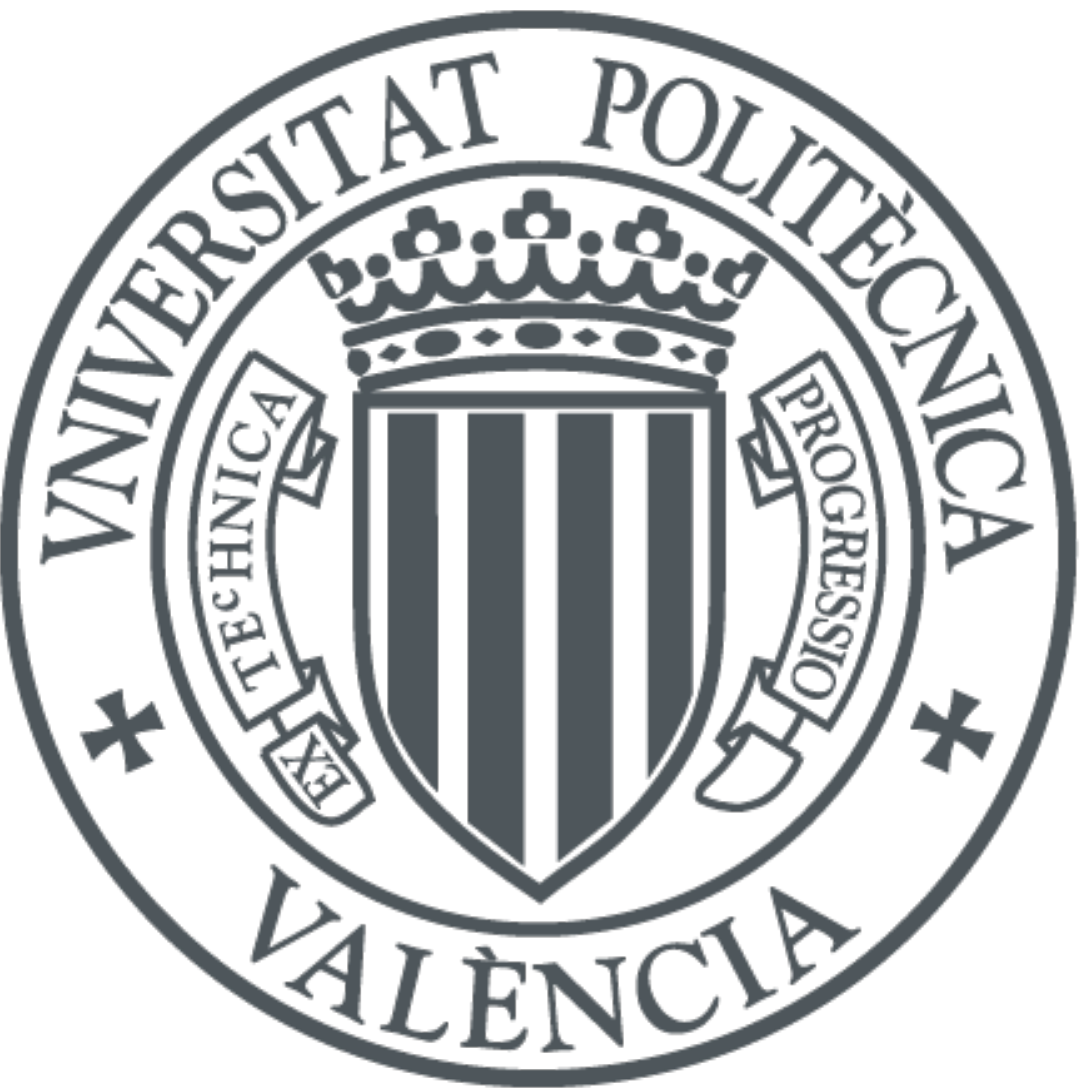

The final publication is available at

https://doi.org/10.1016/j.istruc.2020.12.005

Copyright Elsevier

Additional Information 


\section{Robustness of steel truss bridges: laboratory testing of a full-scale 21-metre bridge span}

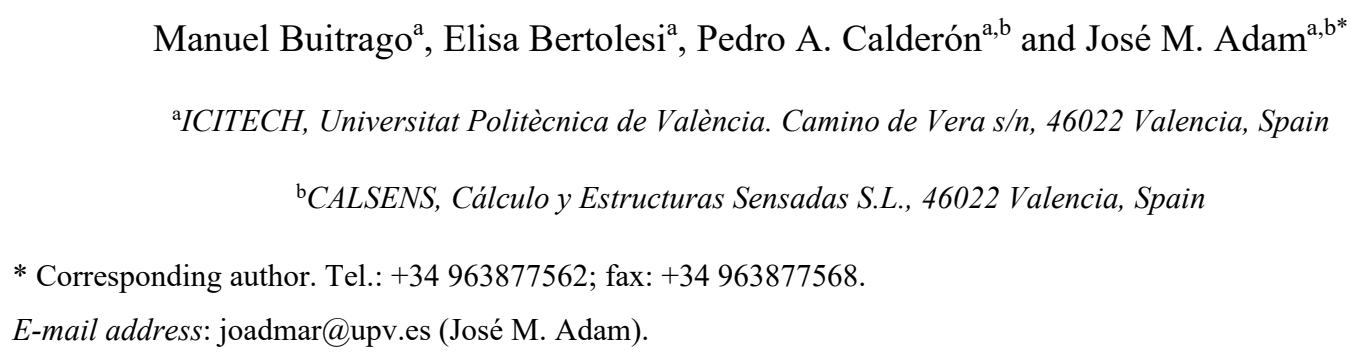

\section{Abstract}

This study aimed to experimentally analyse the robustness of riveted steel bridges based on truss-type structures and to define practical recommendations for early detection of local failures before they cause progressive structural collapse. Although there are many experimental studies on robustness and progressive collapse on buildings, those on bridges are either theoretical or deal with actual collapses. This paper describes a unique case of a $21 \mathrm{~m}$ full-scale bridge span tested under laboratory conditions with an extensive monitoring system, together with an experimental study to evaluate structural behaviour and robustness as damage or failure progressed in its elements. A linear-static finite-element analysis was also included to examine other possible causes not included in the experiment. The results proved the structural redundancy of this type of truss structure based on the joints' resistance to bending moments and gave rise to a series of practical structural health recommendations to identify early failures and avoid progressive or sudden bridge collapse. The study carried out and the recommendations it produced are now being applied in three similar bridge case studies.

Keywords: robustness; experimental test; structural health monitoring; progressive collapse; steel truss bridges; riveted joints. 


\section{Introduction}

Bridge structures are expected to withstand loads defined in codes (e.g. gravity, wind, snow, etc.); however, these structures may be subjected to extreme events (also called lowprobability/high-consequence events) such as hurricanes, tsunamis, explosions, vehicle impacts, fires, human errors, terrorist attacks [1,2]; or to be exposed to several degradation actions such as corrosion [3] or fatigue [4]. These events can cause the sudden loss of local elements and trigger a cascading failure of the bridge, known as progressive bridge collapse [5].

Some progressive collapse events gained significant public attention due to the extent of damage and number of victims, as for example: the classic Ronan Point in 1968 [6] or the Twin Towers of the World Trade Center in 2001 [7] in buildings, and the I-35 W bridge in Minnesota [8], the Hongqi Viaduct [9] or Ponte Morandi [10] in bridges. The concept of robustness is introduced in present-day design standards to minimise the risk of progressive collapse. According to this concept, although the risk of local failure cannot be neglected, the aim is rather to control its consequences. Robustness can be generally defined as a measure of the ability of a system to remain functional in the event of a local failure in a single component or a series of connected components [11].

Progressive structural collapse is now a hot topic subjected to widespread theoretical and experimental studies on buildings [12-18]. In bridges, the studies focused basically on the numerical or analytical assessment of robustness (e.g. Ghali and Tadros [1], Wang and Zhou [19], Jiang et al. [20]) or the analysis of real cases (e.g. Starossek [5], Bontempi [7], Deng et al. [8]), including truss bridges [21-29] with an unique experimental test [29]. In truss bridges, from a theoretical viewpoint $[21,23,27]$, it has been shown that a failure in any element can trigger partial or total bridge collapse, so that there is a need for further experimental studies to analyse the real behaviour of these bridges to serve as the basis of future theoretical and numerical developments.

This paper describes the research team's unique opportunity to study a full-scale steel-riveted truss bridge with the double aim of: 1) an experimental analysis of its robustness, and 2) establish 
progressive collapse. The study was both ambitious and novel and permitted an advance in two

54 areas, including i) the analysis of robustness in the local failure of some elements and ii) structural

55 health monitoring to prevent progressive collapse.

56 To comply with these aims, after this section a brief description of the bridge is given in

57 Section 2, the test is described in Section, 3 including the transport of the span to the laboratory,

58 the test set-up, procedures and instrumentation used. The experimental results are discussed in

59 Section 4 and are amplified in Section 5 with the aid of computational models. The knowledge

60 obtained from the experimental and theoretical studies was used as the basis for a series of

61 recommendations for early detection of local failures in elements (Section 6) and conclusions are

62 given in Section 7.

63

64 2. Description of the bridge

65 The railway bridge studied was built between 1913 and 1915 and so was more than 100 years

66 old. Its structure was formed by a series of Pratt type trusses connected by riveted joints. It also

67 had a series of horizontal and vertical braces in the form of St. Andrew's crosses, and longitudinal

68 and transverse beams to locally distribute train loads to the Pratt trusses. The heights of the metal

69 piers varied up to $23.6 \mathrm{~m}$, and it had two isostatic spans at each end (span length ranged from

$7021.1 \mathrm{~m}$ to $21.5 \mathrm{~m}$ ) with a continuous beam in the two central spans ( $42.0 \mathrm{~m}$ each). All the supports

71 were hinged with free rotations. One support in each span also had free longitudinal displacement

72 as a roller (A1 for span 1, P1 for span 2, P2 for span 3, P4 for span 4, P5 for span 5 and A2 for

73 span 6). Fig. 1 gives the principal bridge dimensions and a view of a train passing over it. 

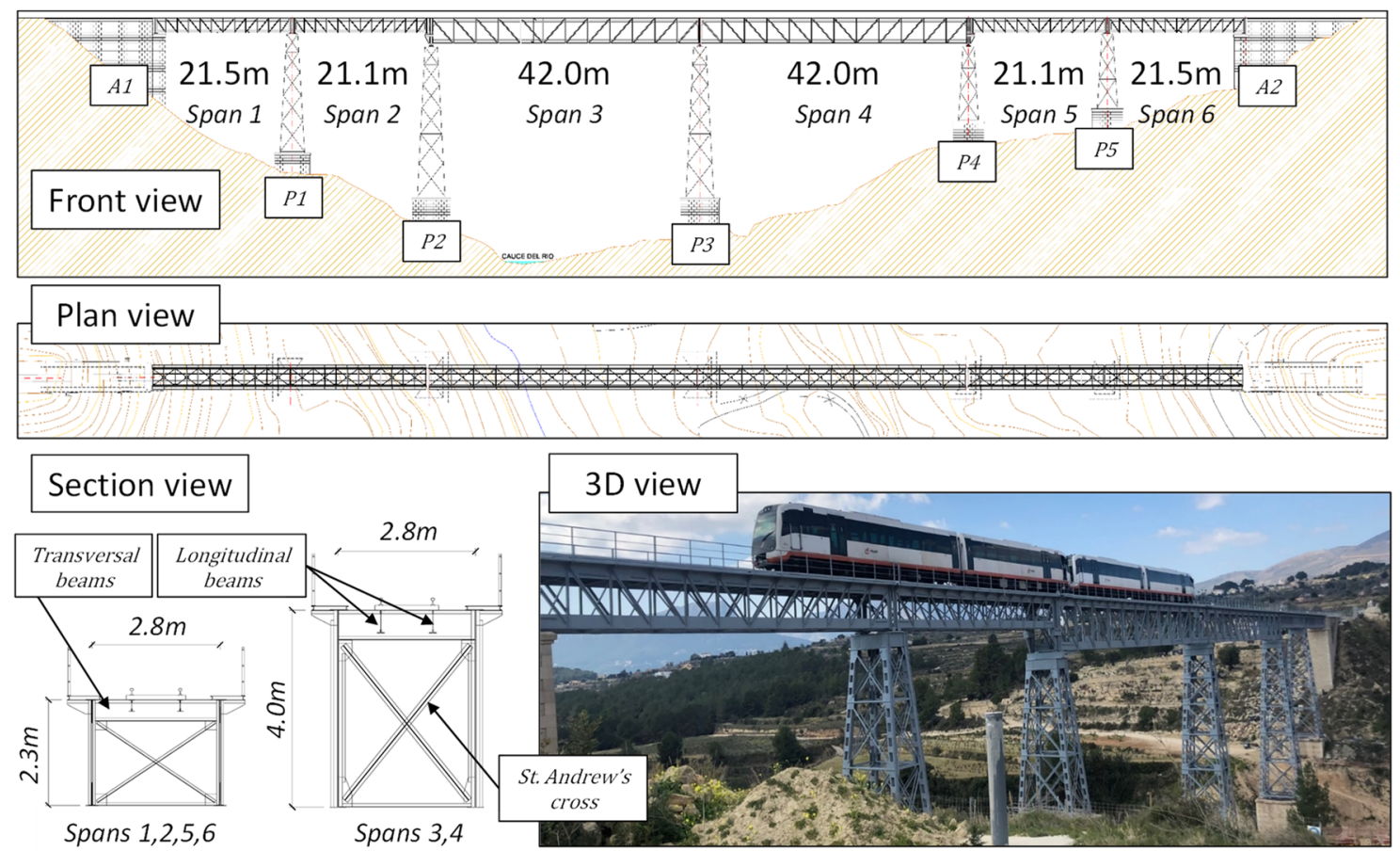

Figure 1. Geometry of the bridge and general views.

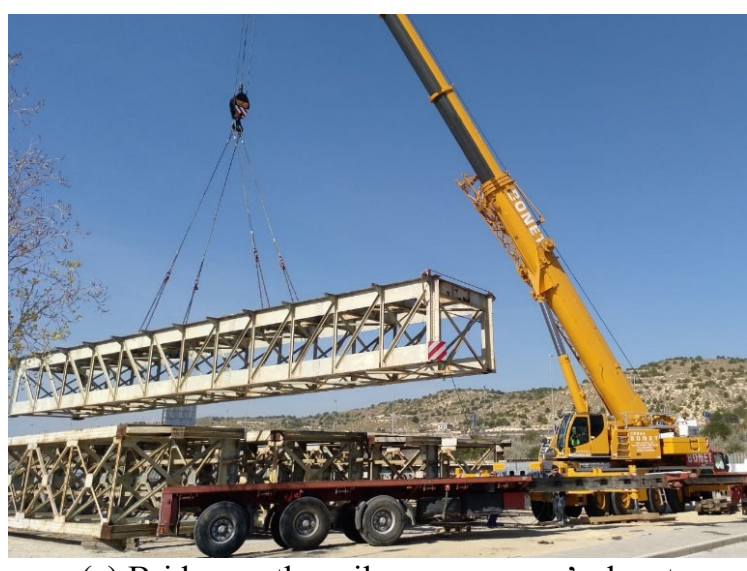

(a) Bridge on the railway company's depot

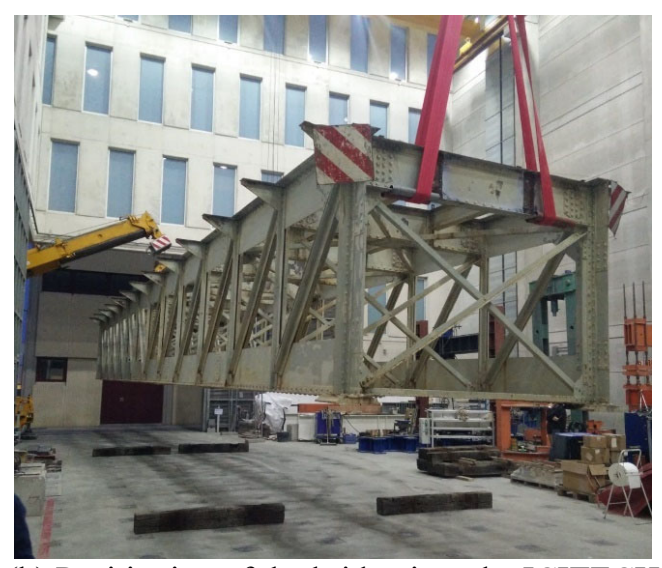

(b) Positioning of the bridge into the ICITECH laboratories

Figure 2. Transport and reception into the ICITECH laboratories.

\section{Experimental test}

\subsection{General}

The study was carried out on one of the isostatic spans of a twin of the bridge shown in Fig.

801 with the same geometry and year of construction as the one analysed here and had been in

81 service for the same length of time. The span under consideration had the same characteristics as

82 spans 2 or 5 shown in Fig. 1. It had previously been replaced by a new bridge and was stored at 
83 the railway company's depot. This gave to this study a unique opportunity to test a full-scale

84 bridge at the ICITECH laboratories at the Universitat Politècnica de València and transfer the

85 results obtained directly to the bridge under study and to others with the same characteristics. Fig.

86 2(a)-(b) contains a series of photos that illustrate the complex process of transporting the bridge

87 to the ICITECH laboratories.

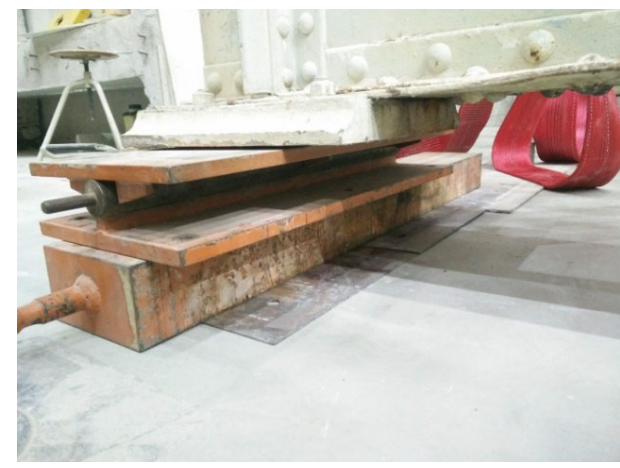

(a) Hinged support

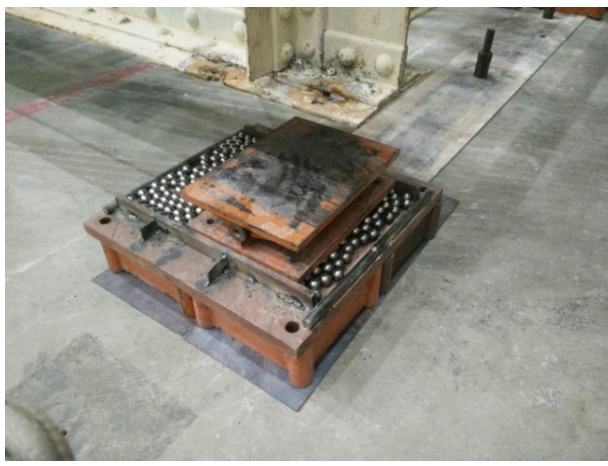

(b) Hinged and roller support

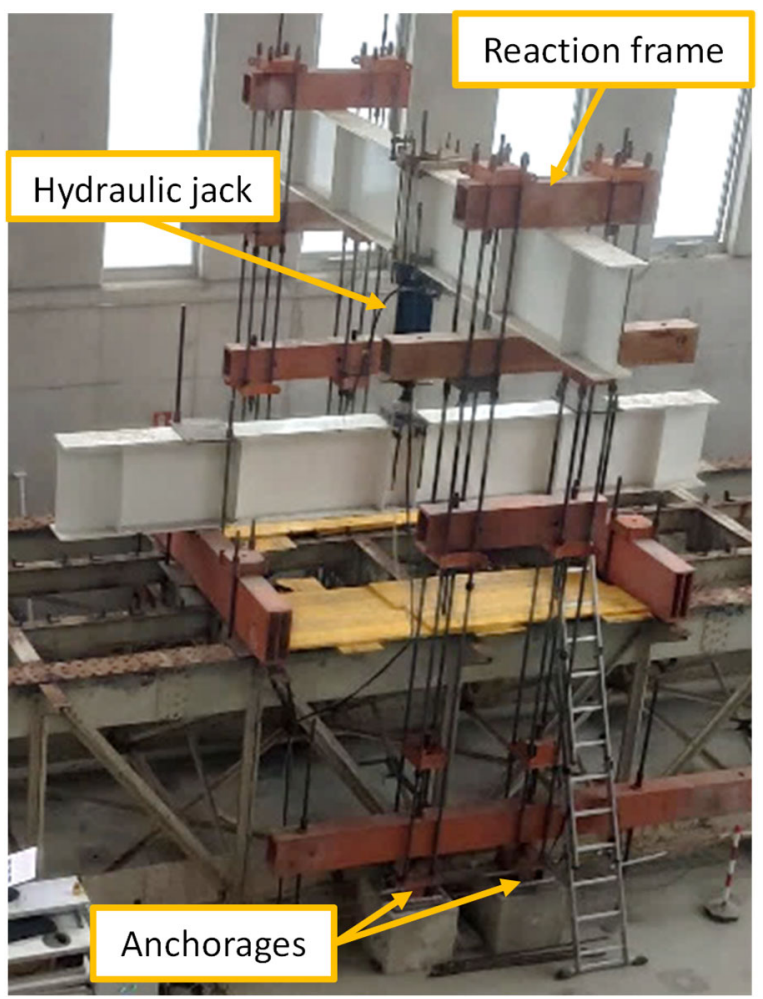

(c) Reaction frame

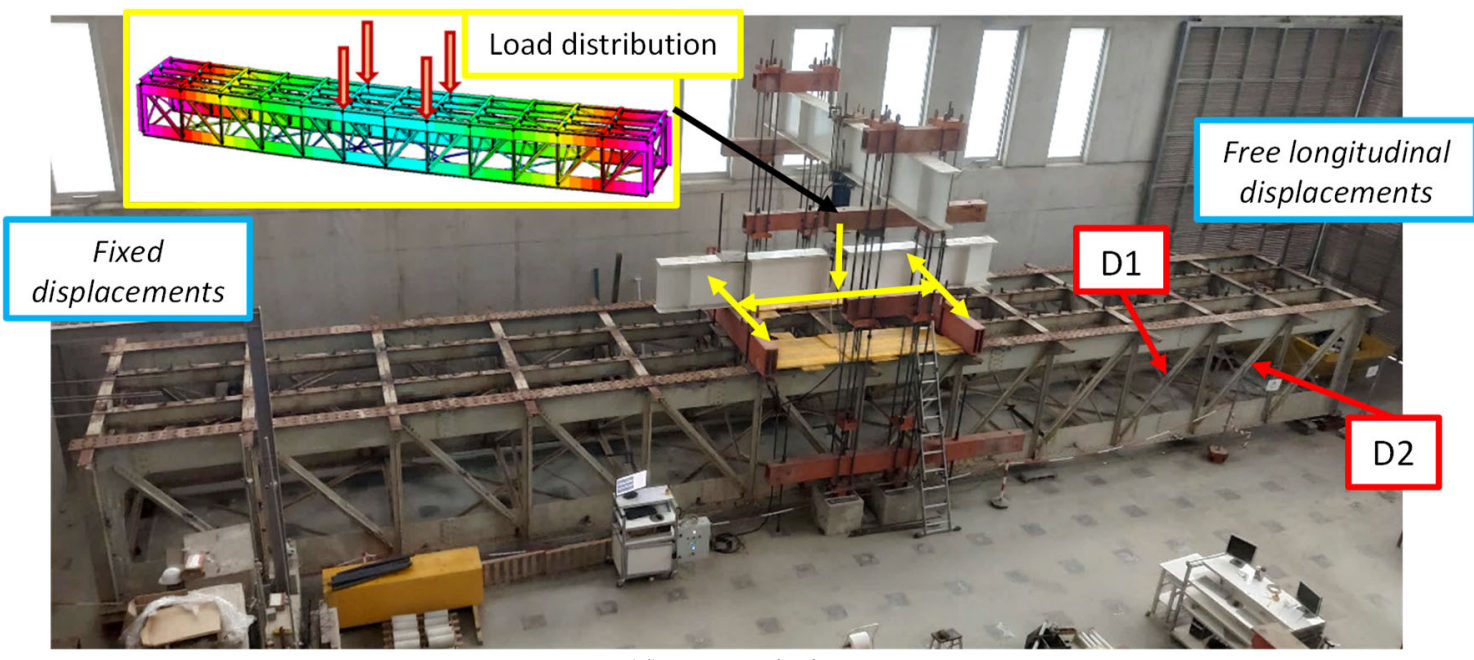

(d) General view

Figure 3. Test set-up. 


\subsection{Test set-up}

The $21.1 \mathrm{~m}$ span had the same support conditions as the originals, with free rotations at both sides and longitudinal displacements on one side only. The supports were reproduced in the laboratory with the help of hinges that allowed free longitudinal rotation and a guided box of steel ball-bearings that allowed longitudinal displacement only in the corresponding supports (See Fig. 3(a)-(b), respectively).

The hydraulic jack with a maximum load capacity of $1300 \mathrm{kN}$ used to test the bridge was installed with the help of a reaction frame at the centre of the span which was anchored to the laboratory's reaction slab. The load applied by the jack was shared between 4 points by a system of metal girders to avoid high load concentrations. The test setup and details of the load distribution system can be seen in Fig. 3(c)-(d).

\subsection{Sequence of damage and load}

Two types of very different approaches can be used to study structural robustness in sudden failures: the scenario-dependent [30] and scenario-independent [13]. The first is used to study and consider the cause of the failure while the second only aims to minimize the consequences, whatever the cause. Both have the common aim of improving robustness by studying the behaviour in sudden local failures in a component. In the present experimental study the scenarioindependent approach was selected to: a) analyse structural robustness after a series of damage to some elements, b) study the structural behaviour after activating Alternative Load Paths (ALPs), and c) establish a number of directives in order to anticipate structural failures that could end in total collapse.

To achieve these objectives a structural damage sequence was designed to analyse behaviour with the evolution of deliberately caused damage. In the test the damage was only caused in the diagonals that had previously been expected to provide effectively activated ALPs. Other more complicated cases such as main chord failure were analysed numerically (see Section 5).

The diagonals selected to reproduce progressive damage with possible sudden collapse were those labelled D1 and D2 in Fig. 3(d) and were chosen as being the most critical both in the test 
117 carried out and in actual service. The load on these diagonals was lower than that on the external

118 diagonal, although strains and stresses were higher due to being smaller sections. Fig. 4 shows

119 the sequence of the damage in the test, in which the shaded section represents the break made to

120 simulate damage evolution. After each damage sequence a load increment of up to $1250 \mathrm{kN}$ was

121 gradually applied with a force-controlled mode and the structural response was determined by the

122 ambitious monitoring system described below.

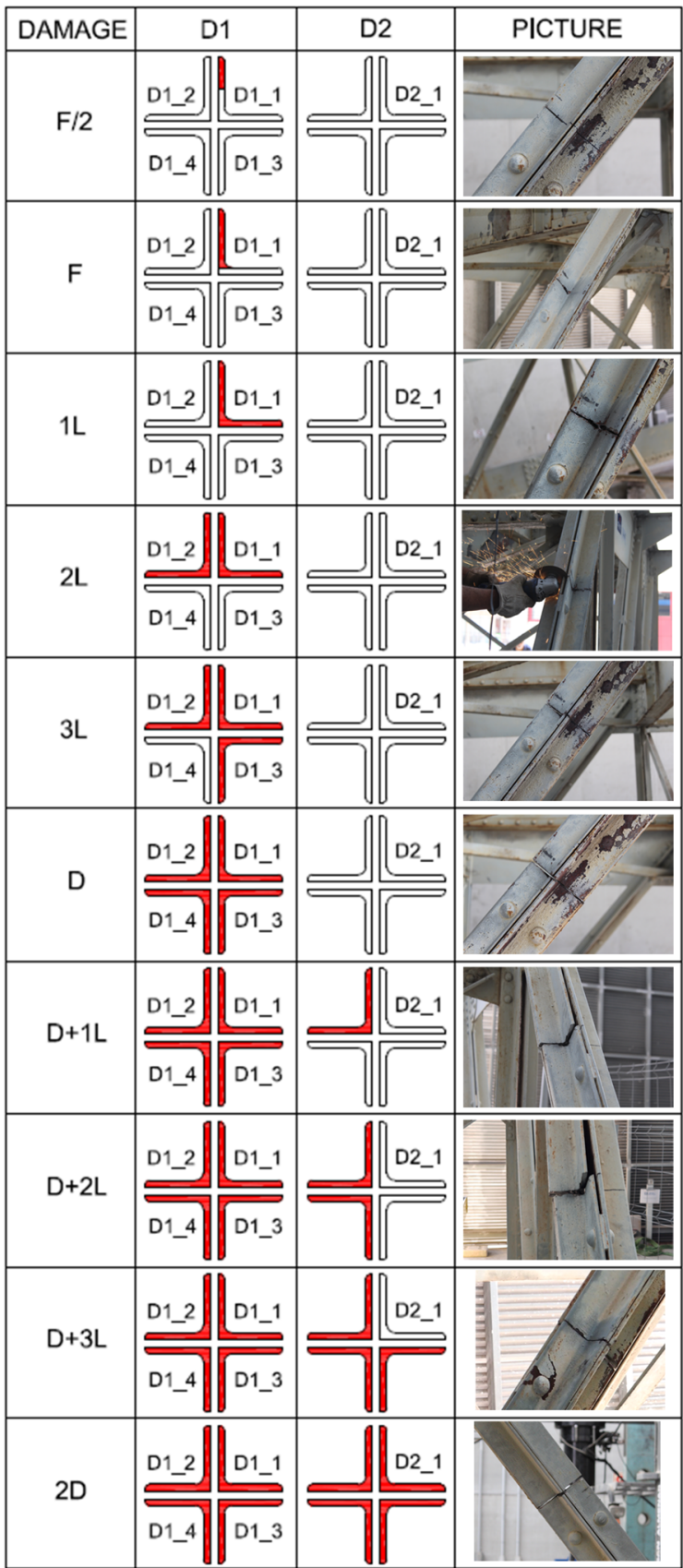

Figure 4. Sequence of damage. 


\subsection{Instrumentation}

127 T in Fig. 5) and 2 fibre optic accelerometers (A in Fig. 5).

128

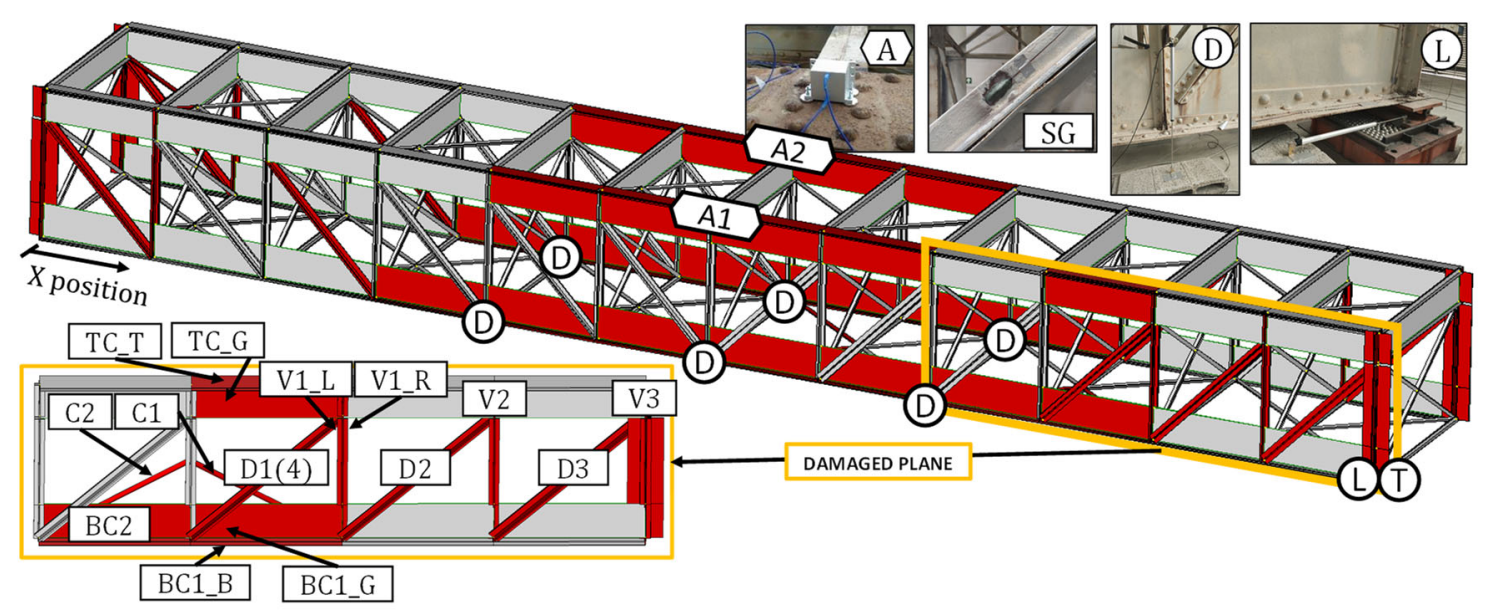

Figure 5. Instrumentation.

The 40 strain gauges were located in different positions on the bridge to analyse the structural response at each damage level (see red elements in Fig. 5). The most important for the study are depicted in Fig. 5. In general, each element only had one strain gauge at the centre of gravity and in the middle of the length. However, diagonal D1 with 4 strain gauges, and vertical column V1 and top (TC) and bottom (BC1) chords with 2 strain gauges each were more intensively monitored, as can be seen in Figs. 4-5. The sensors for D1 were installed on the L-profiles of the diagonal, at mid-length (see Fig. 4). In the case of V1 (see Fig. 5), the sensors were installed on the upper left (V1-L) and right (V1-R) where modifications of the deformations were expected as damage intensified (see Section 4 and 5 for further details). The two sensors at V1 were installed just before the test for level 3L damage. For the top and bottom chords (see Fig. 5) they were placed on the external surface (TC_T and $\left.\mathrm{BC} 1 \_\mathrm{B}\right)$ and at the centre of gravity of the elements (TC-G and BC1_G).

LVDTs measured bridge deflection (D) and longitudinal displacement (L) in the mobile support during the test. For safety reasons possible sideways displacements were also controlled (T) (see Fig. 5). 
The accelerometers were placed at the mid-span (see Fig. 5) to measure the eigenfrequency

146 of the first vertical vibration mode. The value was determined by measuring acceleration after an

147 impact at mid-span after the test at each damage level.

\section{Test results. Analysis and discussion}

\subsection{Strain gauges}

Fig. 6 shows the stresses obtained in diagonals from the readings of strain gauges after each

152 damage level. The stresses are seen to decline as the breaks were made in diagonal D1, except in 153 sensor D1_4 belonging to the last damaged L-profile. The reduction of the diagonal D1 cross154 section by the previous breaks increased the stresses by up to $53 \%$ the L-profile monitored by sensor D1_4.

156

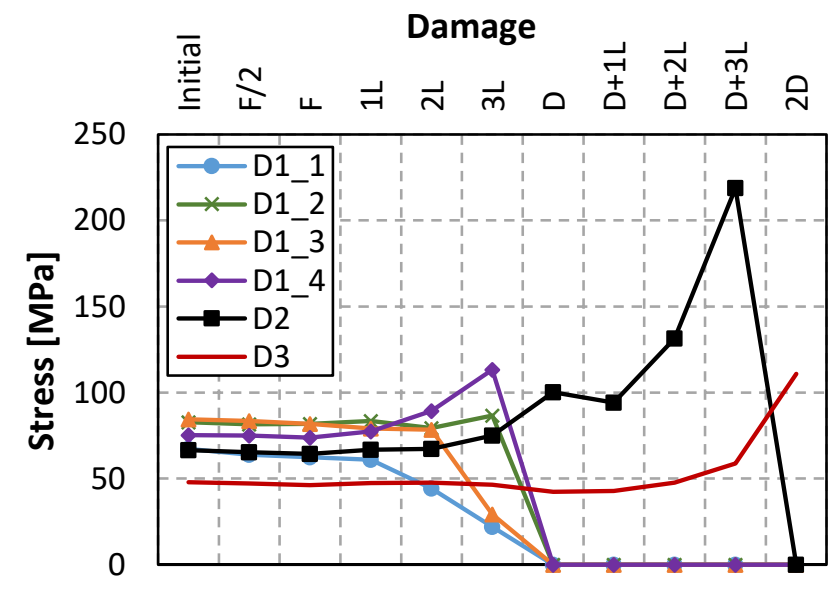

Figure 6. Stresses in diagonals D1, D2 and D3.

Up to the complete break of the first diagonal (level of damage D; see Fig. 6), the sensors on D2 and D3 did not show any significant changes. The stresses only increased in diagonal D2 after damage 3L but this was not really significant until D1 was completely broken (damage level D) and breaks began to be made in D2, which subsequently suffered much higher stresses of up to 240\%. D3 did not register a significant stress increase (up to 136\%) until three L-profiles in diagonal D2 were broken (damage level D+3L). This shows that the diagonals beside the damaged one do not experience significantly higher loads until the area of the damaged one has been reduced by $75 \%$, which indicates: a) the shear distribution in the Pratt truss remains similar until 
166 a diagonal has been completely broken, and b) ALPs must be activated on complete breakage of

167 a diagonal (damage level D and 2D) (analysed in detail below), which significantly raises the

168 loads on the neighbouring diagonals. This load increase on these diagonals cannot be explained

169 simply by the different load distribution theoretically expected for a Pratt truss since the shear of

170 the span did not change (it is important to note that truss elements usually work only under axial

171 loads to transmit the shear and bending moments of the span to the supports).

172 Fig. 7 shows the stresses obtained for each damage level in the tests in vertical column V1

173 and crosses $\mathrm{C} 1$ and $\mathrm{C} 2$. The results for V1 confirm the activation of ALPs after complete failure

174 of a diagonal, with significant higher stresses at damage levels $\mathrm{D}$ and $2 \mathrm{D}$. The vertical column

175 starts mainly from compression plus small bending and finishes with serious bending plus

176 compression, sensor V1_L being in compression and V1_R in tension. However, sensor V2 (and

177 V3, not shown in Fig. 7), which was installed at mid-height of the vertical column, was not able

178 to measure any significant change due to the insignificant bending in the middle of the vertical

179 columns. The analysis thus shows that: a) damage to the diagonals can only be registered by

180 sensors at the ends of vertical columns, and b) the highest absolute stress values were recorded in

181 the compressed part of these elements, which improved the sensors' accuracy.

182

183

184

185

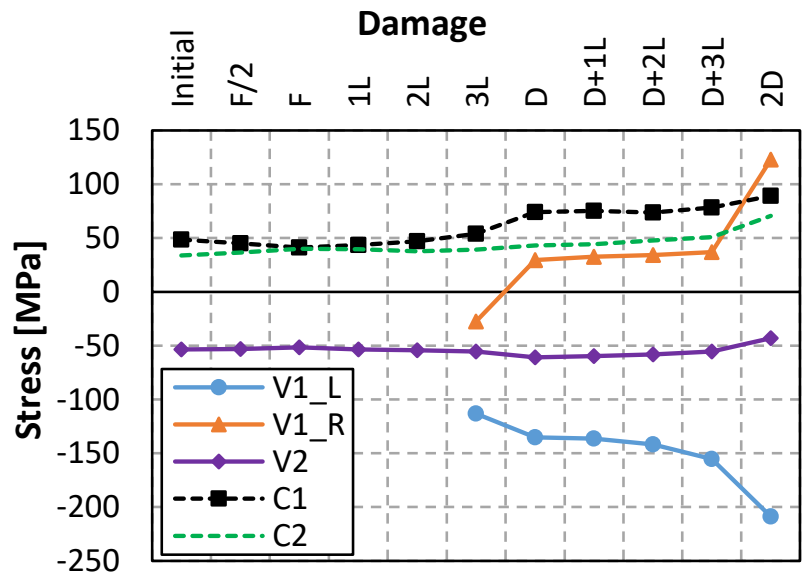

Figure 7. Stresses in vertical columns $\mathrm{V} 1$ and $\mathrm{V} 2$ and horizontal crosses $\mathrm{C} 1$ and $\mathrm{C2}$.

Crosses $\mathrm{C} 1$ and $\mathrm{C} 2$ were also affected by the damage (see Fig. 7). Although stress increments were not as significant as those in the vertical columns, cross $\mathrm{C} 1$, which was closer to the damage, 
also registered a stress increment up to $85 \%$. This increment means that the structure was trying

187 to reduce the distortion caused by a more flexible Pratt truss (in the damaged plane) to the overall

188 structure than the more rigid Pratt truss on the undamaged plane.

189 Fig. 8 shows the stresses obtained in the tests after each damage level in bottom (BC1_B and

190 BC1_G) and top (TC_G and TC_T) chords. The sensors detected a marked rise of the bending

191 moment in both chords, with lower measured values at the centre of gravity $(\mathrm{G})$ than those

192 measured at the external part of the element (B and $\mathrm{T}$ for bottom and top chord, respectively).

193 This shows that: a) bending was induced in the chords by the damage, b) the biggest stress change

194 were at the ends of the chords due to the stronger bending effect. It is important to remember here

195 that the sensors, as shown in Fig. 5, were placed close to a joint and not at the element's mid-

196 length (a more detailed discussion can be found in Section 5). The sensor on bottom chord BC2

197 (not shown in Fig. 8), which was installed at its centre of gravity and mid-length did not register

198 any significant change during the test.

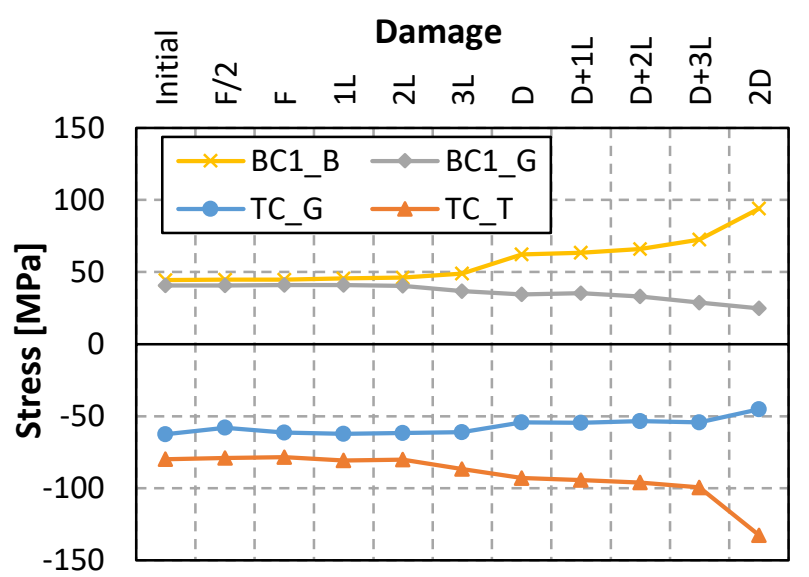

Figure 8. Stresses in top (TC_T and TC_G) and bottom (BC1_B, BC1_G and BC2) chords.

\subsection{Deflections}

Fig. 9 shows the deformed shape of the damaged and the undamaged Pratt truss (damaged and undamaged plane, respectively) during the damage and test sequence. The behaviour of both trusses is markedly different. Deflections measured on the undamaged truss were not affected by the damage sequence with a maximum vertical deflection at mid-span slightly over $25 \mathrm{~mm}$. 
207 However, deflections on the damaged plane were strongly affected by the damage sequence,

208 starting with the same deflection $(25 \mathrm{~mm})$ and ending with $40 \mathrm{~mm}$ deflection at mid-span.

209 Measuring deflections on the damaged plane can thus be considered an effective way of

210 interpreting damage by registering significant changes in both the maximum value and deformed

211 shape, which was greater on the right (position $\mathrm{X}$ between $10.6 \mathrm{~m}$ and $21.1 \mathrm{~m}$ ).

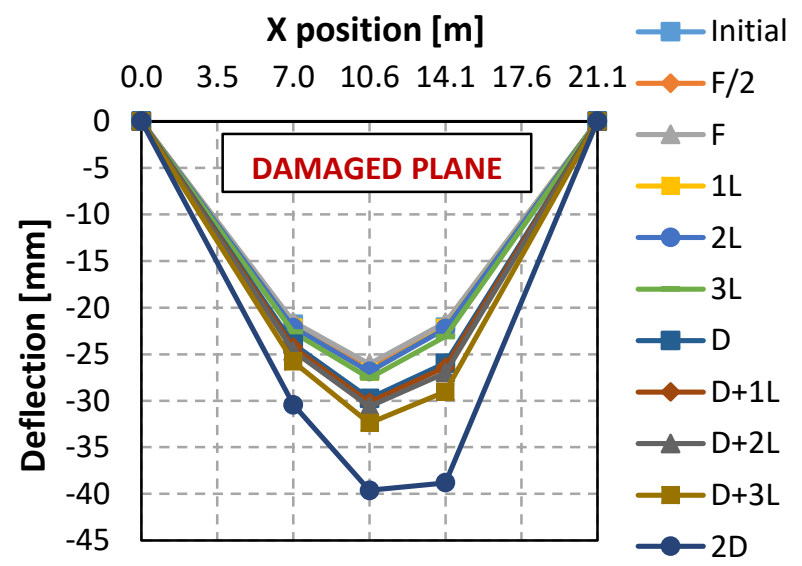

(a) Damaged plane

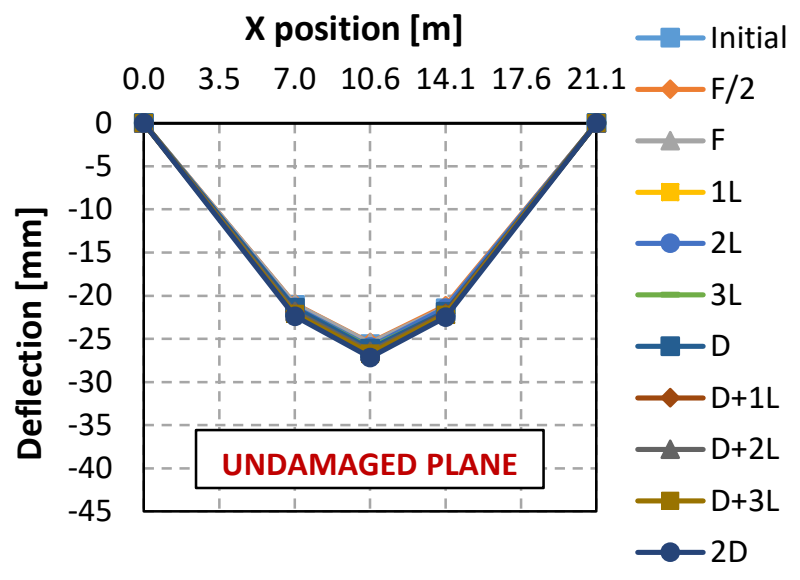

(b) Undamaged plane

Figure 9. Evolution of deflections.

\subsection{Horizontal displacements}

215 As horizontal displacements remained small during the different test damage levels, with a

216 maximum of $5 \mathrm{~mm}$ for the longitudinal one, they could not be regarded as a reliable indicator of

217 structural damage. Transversal displacement stayed close to 0 and confirmed that the supports

218 installed for the tests worked well. 


\subsection{Vibrational modes}

The accelerometers A1 (in the damaged Pratt truss) and A2 (in the undamaged Pratt truss)

221 installed at mid-span gave the eigenfrequencies of the structure's first vertical vibration mode.

222 Fig. 10 gives the results obtained together with the accelerometer A1 trend line. It can be seen 223 that the first vertical vibration mode falls as damage is increased and the reduced frequency levels are similar for both $\mathrm{A} 1$ and $\mathrm{A} 2$.

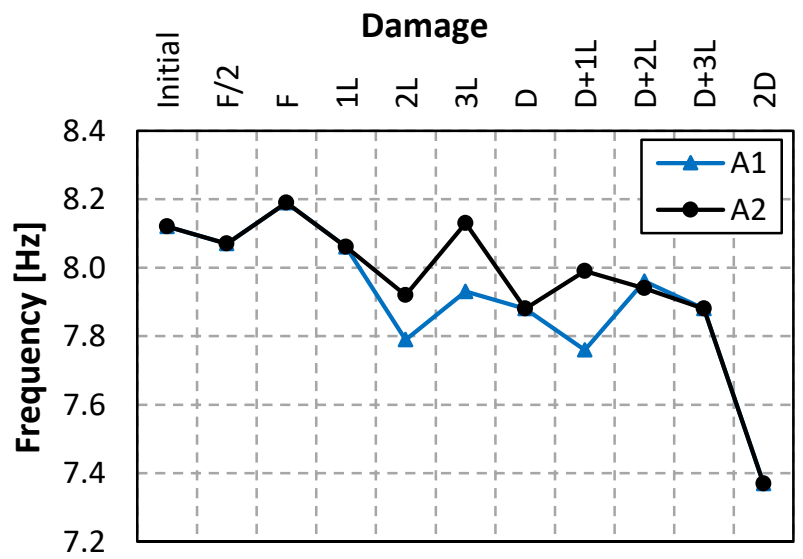

Figure 10. Evolution of the first vibration mode.

\subsection{Discussion}

The span under study consisted of Pratt trusses considered as externally and internally isostatic working under axial forces only. Consulting companies usually consider these types as structures of truss elements with hinges at the ends. If this had been true the present study would not have been possible since it would have lacked structural redundancy. However, the structure was shown to have the ability to adapt to the total failure of key elements such as diagonals.

234 This adaptability was possible thanks to the effective activation of ALPs. In this case the structure, which worked basically under axial forces, made use of the structural redundancy of the joints to adapt to the failure of diagonals, as the joints were able to resist high bending moments. Thanks to this ability, when the diagonals failed, the structural behaviour of the affected zone changed from Pratt truss to Vierendeel behaviour (same structure but without diagonals; see Fig. 11), in which the capacity of the joints to resist bending moments is crucial. When a structure 
240 like the span under study has no diagonals, the structure is known as a Vierendeel beam, and the

241 load transmission to the foundations is only possible with the help of the moment-resisting 242 capacity of joints. The moments registered in the vertical columns and top and bottom chords (see 243 Section 4.1) confirm this hypothesis (see also Section 5).

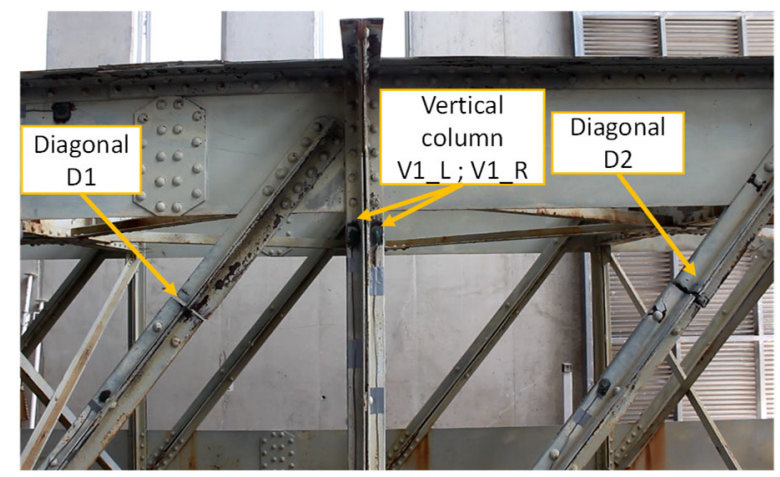

Figure 11. Deformed shape during the test after level of damage 2D.

\section{Finite Element Modelling}

A Finite Element Analysis (FEA) [31] could be used to analyse other failures not considered in the experiment. The FE model reproduced the bridge geometry through BEAM elements fully connected and with a combination of BEAM and SHELL elements for the top and bottom chords to fit the numerical results better to the actual structural behaviour (steel elastic modulus of 210GPa and density equal to $78.5 \mathrm{kN} / \mathrm{m}^{3}$ ). The boundary conditions applied were identical to those in the test with fixed displacements and free rotations in the four supports. The supports at $\mathrm{X}=$ 21.1m also had free longitudinal displacements. Fig. 12 shows the FE model of the bridge span.

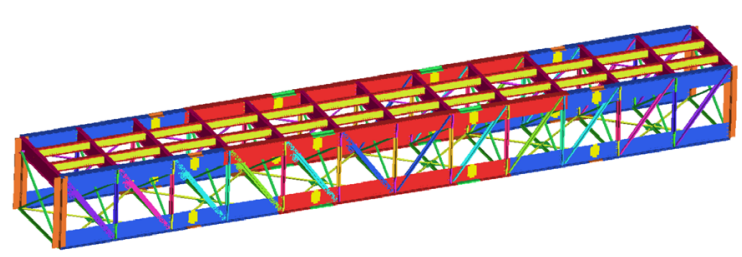

Figure 12. FE model. 


\subsection{Reproduction of the test failure schemes}

261 Firstly, a modal analysis was carried out to compare the frequency of the first vertical

262 vibrational mode of the original structure and the structure without diagonals D1 and D2 with the

263 experimental results. Table 1 gives the numerical and experimental results obtained and the

264 frequency reduction in both cases for damage levels D and 2D. The numerical results can be seen

265 to reproduce the experimental results, with similar frequency reduction percentages to those 266 obtained in the test.

267 Table 1. Comparison of frequencies between numerical and tests results.

\begin{tabular}{ccccc}
\hline \hline & & \multicolumn{3}{c}{ Level of damage } \\
\cline { 3 - 5 } & & Initial & $\mathrm{D}$ & 2D \\
\hline \multirow{2}{*}{ Experimental } & Frequency [Hz] & 8.12 & 7.88 & 7.37 \\
& Reduction [\%] & --- & 2.96 & 9.24 \\
\hline \multirow{2}{*}{ Numerical } & Frequency [Hz] & 8.72 & 8.53 & 7.95 \\
& Reduction [\%] & --- & 2.18 & 8.83 \\
\hline
\end{tabular}

Secondly, Linear-Static Finite-Element Analyses (LSFEAs) were performed for different damage levels (Initial, D and 2D) considering geometrical nonlinearities. A steel elasticity modulus of $210 \mathrm{GPa}$ was considered with the application of a load of $1250 \mathrm{kN}$, as in the test. Fig. 13 shows the deformed shape and stresses of the structure (in the damaged plane) for the different levels. Both deformed shape and stresses are similar to those obtained experimentally. The

274 numerical analysis again shows the activation of ALPs mentioned in Section 4.5, since as damage

275 rose the bending moments also increased considerably causing the different elements (vertical

276 columns and top and bottom chords) to be subjected to high stress gradients in specific sections

277 close to joints (see Fig. 13). This shows that the LSFEA numerical simulation reproduced the experimental behaviour and that the models were properly built. This analysis can thus be extended to failures of other more affected elements not considered in the experiments such as

280 the most heavily loaded bottom chord, which would be extremely difficult to analyse 281 experimentally and safely in a laboratory. 


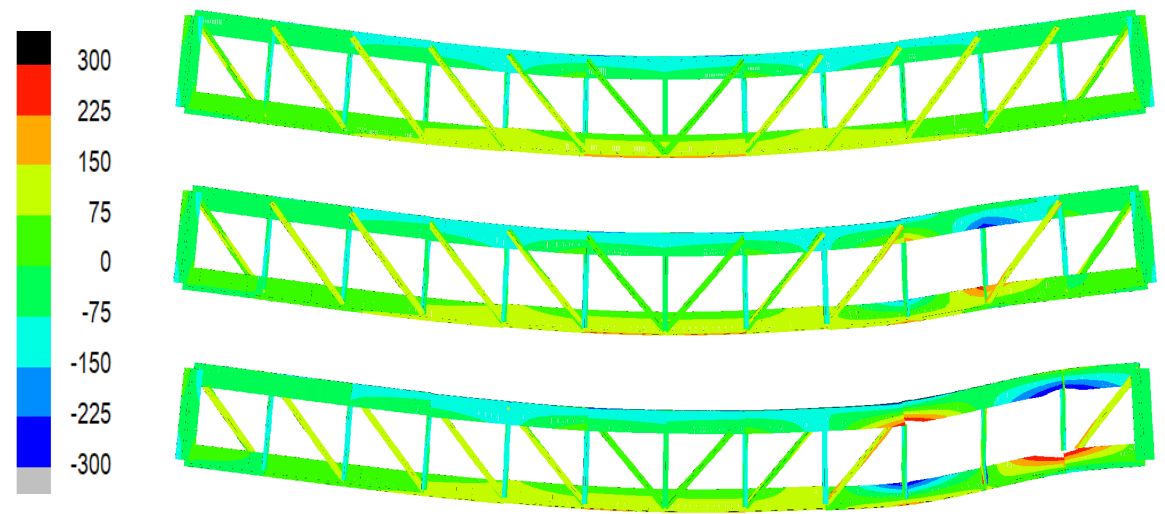

Figure 13. Total stresses for Initial, D and 2D damaged levels. Units: MPa.

\subsection{Failure of the most heavily loaded bottom chord}

This case was analysed by LSFEAs for two damage levels: 1) a section flange failure and 2) complete section failure (see Fig. 14(b)-(c)). All three cases (initial plus two damage levels) were assessed under the same loading scheme described in the previous sections, with a maximum load of $1250 \mathrm{kN}$.

In the most heavily loaded bottom chord flange failure, small increases were found in the stresses on neighbouring elements, especially those due to higher bending moments, although, like the deformed shape, these increases were not significant. In fact, Figs. 14(a)-(b) do not show any significant differences of structural behaviour, indicating that significant ALP activation was not necessary. The Pratt trusses were able to carry on efficiently working the elements mainly under axial loads. In the natural frequencies, the first vertical vibrational mode frequency changed slightly from $8.72 \mathrm{~Hz}$ to $8.71 \mathrm{~Hz}$.

In the complete section failure of the most heavily loaded bottom chord significant structural behavioural differences were found (see Figs. 14(a)-(c)). The numerically reproduced damage (Fig. 14(c)) was quite severe, eliminated Pratt truss-type behaviour close to the failure, and the top chord was the main element in resisting bending moments and axial and shear forces. There

300 were also stress changes in the elements close to the failure, the deformed shape was also

301 significantly different and the first vertical vibrational mode frequency changed from $8.72 \mathrm{~Hz}$ to 6.70Hz. In this case the structure did have to find an effective ALP and passed from Pratt truss to 
303 a basically Beam-type top chord behaviour in the failure zone. All of the parameters used

304 (stresses, deformed shape, natural frequencies) were good indicators of the computer-simulated

305 failure.
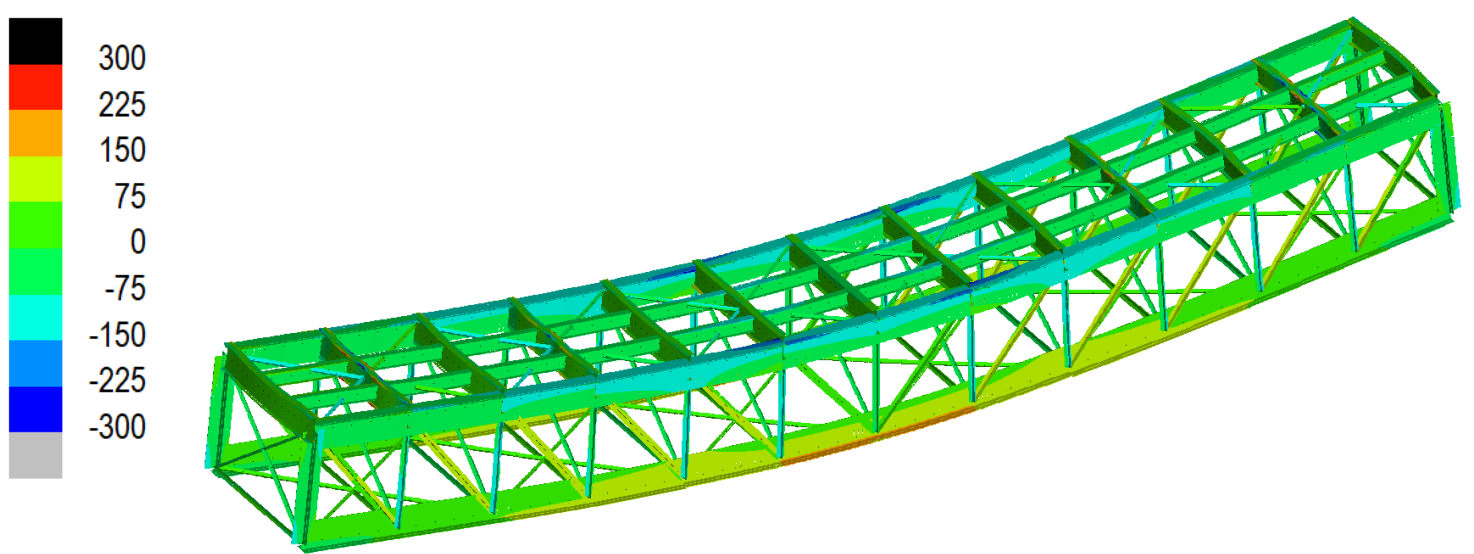

(a) Initial
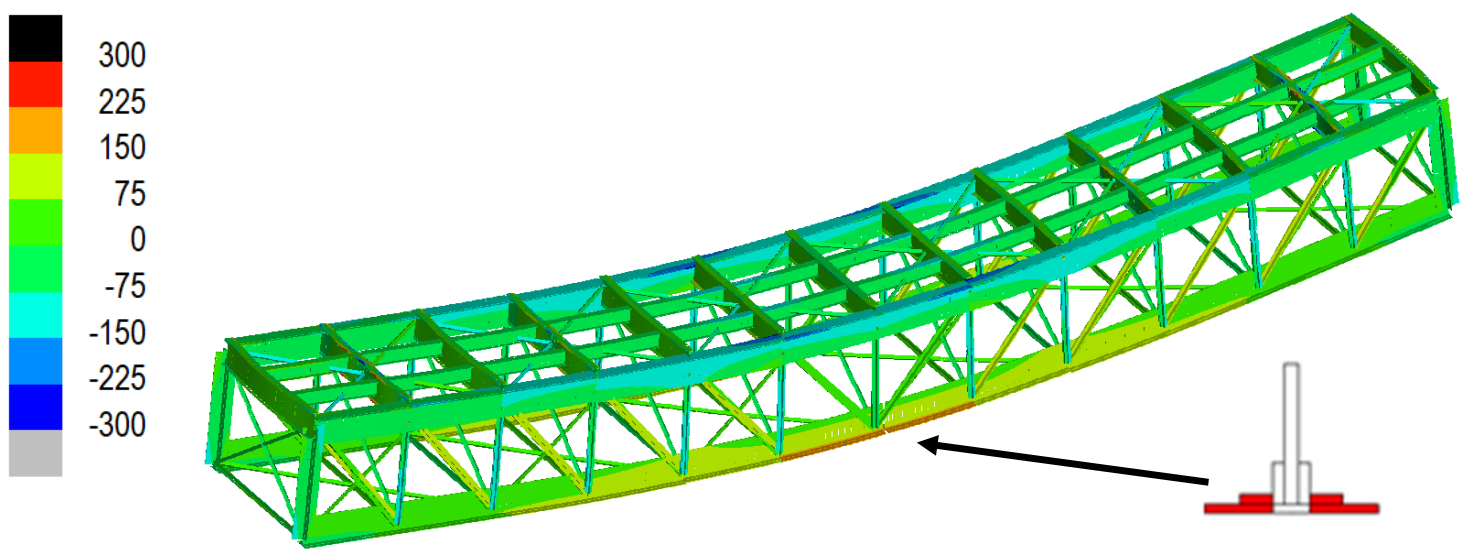

(b) Failure on the flanges (red colour)
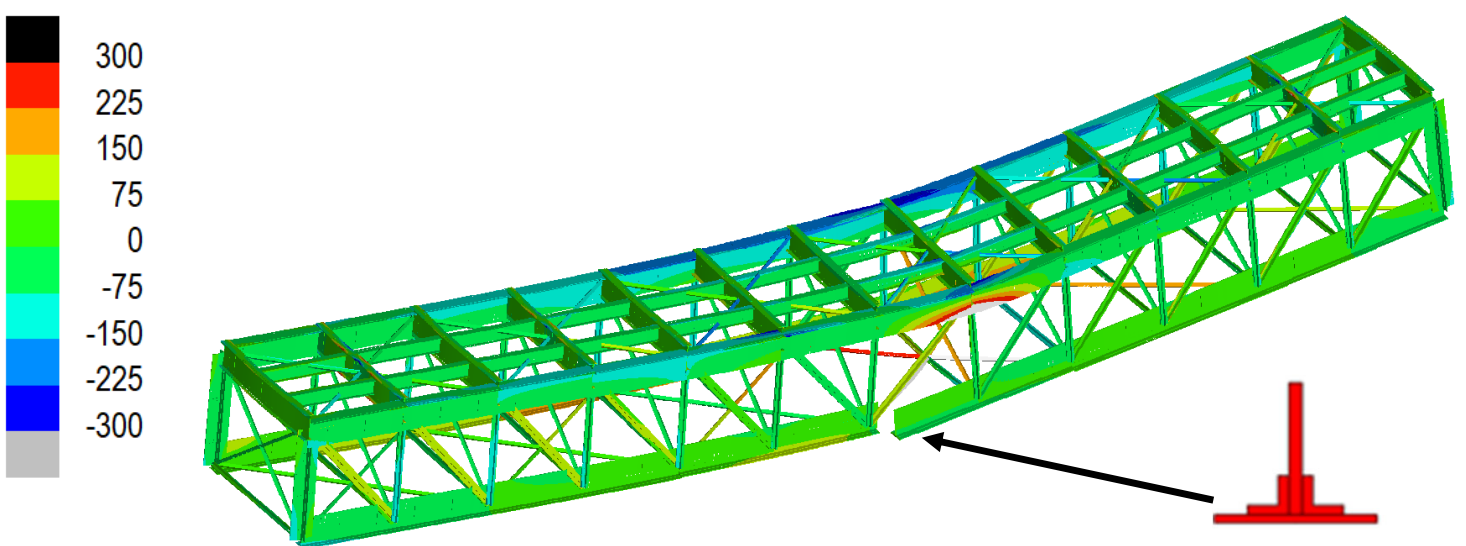

(c) Failure of a complete section (red colour)

Figure 14. Total stresses for the different damage levels in the failure of the most heavily loaded bottom chord. Units: MPa. 


\section{Practical recommendations for Structural Health Monitoring}

310 Based on the results obtained, this section aims to lay down a series of recommendations for

311 real-time monitoring of structures similar to the type studied here for early failure detection,

312 including aspects such as: a) parameters to be controlled, b) appropriate sensors for different

313 parameters and c) a specific location for each type of sensor.

314 Firstly, it is recommended to monitor element deformation by strain gauges. As found

315 previously, the breakage or damage progress of an element and its neighbours is reflected by its

316 deformation. It is thus recommended to arrange sensors around the structure on its most critical

317 elements, for example strain gauges in the external diagonals and vertical columns (maximum

318 shear) and chords near the mid-span (maximum bending) both for conventional monitoring (e.g.

319 load tests) and early failure detection. Strain gauges should be installed at the centre of gravity

320 and the centre of the elements to measure axial loads in truss structures (theoretically, elements

321 are only subjected to axial loads in truss structures). However, other sensor locations are

322 recommended to detect early failures, such as away from the section's centre of gravity and closer

323 to the joints instead of at the centre. Besides considering the effect of failure on the axial load on

324 the element at these points, the considerable effects of the bending moments with effective ALPs

325 in action to cover structural failure will also be included. Sensors can also be placed on elements

326 expected to be subjected to higher instead of reduced deformation in order to reduce measurement

327 errors. Table 2 gives a summary of all this information with recommendations for monitoring and

328 early failure detection of the different elements. 


\begin{tabular}{|c|c|c|c|}
\hline \multirow[b]{2}{*}{ Element } & \multirow[b]{2}{*}{ General purpose } & \multicolumn{2}{|c|}{ Early failure detection } \\
\hline & & General position & $\begin{array}{l}\text { Additional details. To be } \\
\text { measured in case of failure }\end{array}$ \\
\hline Chords & \multirow[t]{2}{*}{ Section: Centre of gravity } & \multirow{2}{*}{$\begin{array}{l}\text { Section: far from the centre of } \\
\text { gravity }\end{array}$} & $\begin{array}{l}\text { Compression and tension } \\
\text { increments in the top and bottom } \\
\text { chords, respectively }\end{array}$ \\
\hline Diagonals & & & Tension increments \\
\hline Vertical columns & $\begin{array}{c}\text { Position: Centre of the length } \\
\text { of the element }\end{array}$ & Position: close to a joint & $\begin{array}{l}\text { Compression increments. In } \\
\text { general, in the point of the } \\
\text { element closer to the centre of } \\
\text { the bay }\end{array}$ \\
\hline
\end{tabular}

Secondly, it is recommended to monitor deflections by any of the different methods, for

332 example topography or LVDTs. As in conventional monitoring, it is generally enough to measure

333 deflection at one point at mid-span, although early failure detection may require monitoring

334 deflection at other points (see Fig. 9). Full monitoring can be carried out by measuring deflection at two points at mid-span and at a quarter and three quarters the length of the span (4 extra points) as was done in the test in the present study (see Fig. 5). This is important to identify the site of

337 the failure.

338 Finally, as can be extracted from the experimental and numerical results, accelerations can 339 also be measured in a bridge to obtain the principal structural vibration modes in real time. All

340 types of structural anomalies can be reflected by small changes in the frequencies of the 341 structure's main vibrational modes. It is recommended to install at least two accelerometers for 342 the control of the first vertical vibrational mode ( 1 accelerometer at mid-span is sufficient). A 343 more complete system would also include two additional accelerometers in each span, one also

344 in the middle of the span but on the opposite frame to follow the structure's possible torsional 345 mode, with the other at a quarter or three quarters the length of the span to follow the second 346 vertical vibration mode.

347 All the information obtained from the present study, and its recommendations, are now being applied to three real bridge case studies in an ambitious real-time monitoring system with a system of 350 strain gauges and 46 accelerometers. Deflections are also registered periodically by static 
load tests. The practical recommendations will be validated further in future studies with the data

351 analysis of the above three case studies.

352

353

\section{Conclusions}

This paper described an experimental study of the robustness of a steel riveted truss bridge on getting the opportunity to lab-test a full-scale bridge span. From this test and the subsequent numerical analysis the following conclusions could be obtained:

- The structure, theoretically with truss-type behaviour had structural redundancy based on the joints' capacity to absorb bending moments that increase with the level of damage.

- During the failure and the evolution of the damage to some of the structural elements it was found that:

- The stresses on nearby elements were highest at points close to the joints most susceptible to bending moments with increases of up to $240 \%$.

- There were significant changes in the deformed shape of the structure. Deflections reached $60 \%$ increments.

- The structure was able to find effective alternative load paths (ALPs) and changed its function from Pratt truss to Vierendeel or single-beam behaviour. These ALPs were limited by the structural load levels until some of the elements initiated plastic behaviour.

- A set of practical recommendations were made for structural health monitoring with the aim of identifying early failures. These recommendations were provided for different parameters (strains, deflections, accelerations), and the type, location and number of sensors for a structure with both a basic and an ambitious monitoring system. 
In future work, a further validation of these practical recommendations will be made with the

377 data analysis of three real case studies on different railway bridges in which an ambitious

378 monitoring system with more than 400 sensors was installed.

\section{Acknowledgements}

We would like to express our gratitude to the FGV (Ferrocarrils de la Generalitat

S.A. and CALSENS S.L. for giving us the opportunity to test a bridge at the ICITECH facilities, also to Juan Antonio García Cerezo, of FGV, for his invaluable cooperation and recommendations. We also wish to show our gratitude for the magnificent work on the bridge by Jesús Martínez, Eduardo Luengo and Daniel Tasquer. The tests on the bridge meant that much of the Structures Laboratory was out of service for other work, for which we owe a debt of gratitude to our ICITECH colleagues for their infinite patience and understanding.

\section{References}

391 [1] Ghali A, Tadros G. Bridge progressive collapse vulnerability. J Struct Eng 1997;123:22731. doi:10.1061/(ASCE)0733-9445(1997)123:2(227).

[2] Cha EJ, Ellingwood BR. Risk-averse decision-making for civil infrastructure exposed to low-probability, high-consequence events. Reliab Eng Syst Saf 2012;104:27-35.

[3] Colajanni P, Recupero A, Ricciardi G, Spinella N. Failure by corrosion in PC bridges: a case history of a viaduct in Italy. Int J Struct Integr 2016;7:181-93. doi:10.1108/IJSI-092014-0046.

399

400

401

402

403

404

[4] Zhuang M, Miao C. Fatigue reliability assessment for hangers of a special-shaped CFST arch bridge. Structures 2020;28:235-50. doi:10.1016/j.istruc.2020.08.067.

[5] Starossek U. Avoiding disproportionate collapse of major bridges. Struct Eng Int 2009;19:289-97. doi:10.2749/101686609788957838.

[6] Russell JM, Sagaseta J, Cormie D, Jones AEK. Historical review of prescriptive design rules for robustness after the collapse of Ronan Point. Structures 2019;20:365-73. doi:10.1016/j.istruc.2019.04.011.

[7] Bontempi F. Elementary concepts of structural robustness of bridges and viaducts. J Civ

[8] Deng L, Wang W, Yu Y. State-of-the-Art Review on the Causes and Mechanisms of Bridge Collapse. J Perform Constr Facil 2016;30:04015005. 
doi:10.1061/(ASCE)CF.1943-5509.0000731.

[9] Bi K, Ren W-X, Cheng P-F, Hao H. Domino-type progressive collapse analysis of a multispan simply-supported bridge: A case study. Eng Struct 2015;90:172-82. doi:10.1016/J.ENGSTRUCT.2015.02.023.

[10] Rania N, Coppola I, Martorana F, Migliorini L. The collapse of the Morandi bridge in Genoa on 14 august 2018: a collective traumatic event and its emotional impact linked to the place and loss of a symbol. Sustainability 2019;11:6822. doi:10.3390/su11236822.

[11] Buitrago M, Sagaseta J, Adam JM. Avoiding failures during building construction using structural fuses as load limiters on temporary shoring structures. Eng Struct 2020;204:109906. doi:10.1016/j.engstruct.2019.109906.

419

420

421

422

423

424

425

426

427

428

429

430

431

432

433

434

435

436

437

438

439

440

441

442

443

444

445

446

447

448

[12] Adam JM, Parisi F, Sagaseta J, Lu X. Research and practice on progressive collapse and robustness of building structures in the 21st century. Eng Struct 2018;173:122-49. doi:10.1016/j.engstruct.2018.06.082.

[13] Adam JM, Buitrago M, Bertolesi E, Sagaseta J, Moragues JJ. Dynamic performance of a real-scale reinforced concrete building test under corner-column failure scenario. Eng Struct 2020;210:110414. doi:10.1016/j.engstruct.2020.110414.

[14] Alshaikh IMH, Bakar BHA, Alwesabi EAH, Akil HM. Experimental investigation of the progressive collapse of reinforced concrete structures: An overview. Structures 2020;25:881-900. doi:10.1016/J.ISTRUC.2020.03.018.

[15] Fu Q, Tan K-H. Numerical study on steel-concrete composite floor systems under corner column removal scenario. Structures 2019. doi:10.1016/j.istruc.2019.06.003.

[16] Mucedero G, Brunesi E, Parisi F. Nonlinear material modelling for fibre-based progressive collapse analysis of RC framed buildings. Eng Fail Anal 2020;118:104901. doi:10.1016/j.engfailanal.2020.104901.

[17] Bao Y, Main JA, Noh S-Y. Evaluation of Structural Robustness against Column Loss: Methodology and Application to RC Frame Buildings. J Struct Eng 2017;143:04017066. doi:10.1061/(asce)st.1943-541x.0001795.

[18] Eren N, Brunesi E, Nascimbene R. Influence of masonry infills on the progressive collapse resistance of reinforced concrete framed buildings. Eng Struct 2019;178:375-94. doi:10.1016/J.ENGSTRUCT.2018.10.056.

[19] Wang MR, Zhou ZJ. Progressive collapse and structural robustness of bridges. Appl Mech Mater 2012;193-194:1021-4. doi:10.4028/www.scientific.net/AMM.193-194.1021.

[20] Jiang H, Wang J, Chorzepa MG, Zhao J. Numerical investigation of progressive collapse of a multispan continuous bridge subjected to vessel collision. J Bridg Eng 2017;22:04017008. doi:10.1061/(ASCE)BE.1943-5592.0001037.

[21] Miyachi K, Nakamura S, Manda A. Progressive collapse analysis of steel truss bridges and evaluation of ductility. J Constr Steel Res 2012;78:192-200. doi:10.1016/J.JCSR.2012.06.015.

[22] Garavaglia E, Sgambi L, Basso N. Selective maintenance strategies applied to a bridge deteriorating steel truss. Bridg. Maintenance, Safety, Manag. Resil. Sustain. - Proc. Sixth Int. Conf. Bridg. Maintenance, Saf. Manag., 2012, p. 1764-70. doi:10.1201/b12352-258.

[23] Khuyen HT, Iwasaki E. An approximate method of dynamic amplification factor for alternate load path in redundancy and progressive collapse linear static analysis for steel truss bridges. Case Stud Struct Eng 2016;6:53-62. doi:10.1016/J.CSSE.2016.06.001.

[24] Olmati P, Brando F, Gkoumas K. Robustness assessment of a steel truss bridge. Struct. 
Congr., Reston, VA: American Society of Civil Engineers; 2013, p. 250-61. doi:10.1061/9780784412848.023.

[25] Trong Khuyen H, Eiji I. Linear redundancy analysis method considering plastic region for steel truss bridges. J Bridg Eng 2017;22:05016011. doi:10.1061/(ASCE)BE.19435592.0000999 .

460 [26] Garavaglia E, Sgambi L. Selective maintenance planning of a steel truss bridge based on the Markovian approach. Eng Struct 2016;125:532-45. doi:10.1016/J.ENGSTRUCT.2016.06.055.

[27] Ma X, Han B. Analysis and mitigation of progressive collapse for steel truss girders. 2011 Second Int. Conf. Mech. Autom. Control Eng., IEEE; 2011, p. 1931-4.

[28] Olmati P, Gkoumas K, Brando F, Cao L. Consequence-based robustness assessment of a doi:10.1109/MACE.2011.5987345.

[29] Azizinamini A. Full scale testing of old steel truss bridge. J Constr Steel Res 2002;58:843steel truss bridge. Struct. Congr., Techno-Press; 2013, p. 250-61. doi:10.12989/scs.2013.14.4.379.

[30] Sagaseta J, Olmati P, Micallef K, Cormie D. Punching shear failure in blast-loaded RC 473 slabs and panels. Eng Struct 2017;147:177-94. doi:10.1016/j.engstruct.2017.04.051.

474

[31] ABAQUS v16.4. Abaqus, Theory manual 2016. 